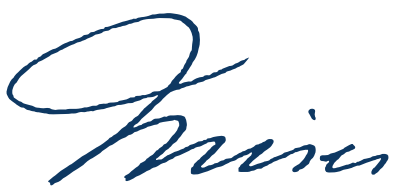

\title{
Pandemia, Crise e Intervenção
}

\author{
Marcos Cantaluppi Plá I (D0000-0002-9514-0529
}

Universidad Rey Juan Carlos, Madrid, Espanha

Resumo: Este artigo está voltado a explicar as consequências econômicas que decorrem de uma pandemia, circunstância em que o advento da crise não é induzido de maneira endógena ao sistema financeiro. A análise está dividida em duas partes. A primeira delas estará voltada aos efeitos que uma doença contagiosa e mortal tem na escala valorativa dos agentes econômicos e em sua preferência temporal e como isso é responsável por distorcer a estrutura produtiva e dar origem a uma crise econômica. Em seguida, passaremos a analisar os tipos de intervenção mais comuns em tempos de pandemia, tais como quarentena, estabelecimento de preços máximos, resgate as empresas e subsídios a determinados agentes. Desta forma, pretende-se explicar como o uso destas políticas acabam por agravar a tragédia e de que maneira o Estado deveria atuar neste cenário.

Palavras-chave: Pandemia, Crise Econômica, Intervenção, Economia, Quarentena.

\footnotetext{
${ }^{\mathrm{I}}$ Marcos Cantaluppi Plá é Mestre em Economia de Escola Austríaca pela Universidade Rey Juan Carlos em Madrid, na Espanha. Email: cantaluppi.marcos@gmail.com
} 


\title{
Pandemia, Crisis e Intervención
}

Resúmen: Este artículo está volcado a explicar las consecuencias económicas que resultan de una pandemia, circunstancia en que el adviento de la crisis no es inducido de manera endógena al sistema financiero. El análisis está dividido en dos partes. La primera de estas estará enfocada a los efectos que una enfermedad contagiosa y mortal tienen en la escala valorativa de los agentes económicos y en su preferencia temporal y cómo esto es responsable por destorcer la estructura productiva y dar origen a una crisis económica. En seguida, pasaremos a analizar los tipos de intervenciones más comunes en tiempos de pandemia, tales como cuarentena, establecimiento de precios máximos, rescate da empresas y subsidios a determinados agentes. De esta forma, se pretende explicar como el uso de estas políticas acaban por agravar la tragedia y de qué manera el Estado debería actuar en este escenario.

Palabras clave: Pandemia, Crisis Económica, Intervención, Economía, Cuarentena.

\section{Pandemic, Crisis and Intervention}

\begin{abstract}
This article aims to explain the economic consequences of a pandemic, a circumstance in which the financial system does not endogenously induce the advent of the crisis. The analysis is divided into two parts. The first one focuses on the effects of a contagious and deadly disease on the economic agents' valuation scale and their time preference and how this is responsible for distorting the productive structure and giving rise to an economic crisis. We will then analyze the most common types of intervention in pandemics, such as quarantine, maximum price setting, bargaining companies, and subsidies to individual agents. It is intended to explain how these policies aggravate the tragedy and how the State should act in this scenario.
\end{abstract}

Keywords: Pandemic, Economic Crisis, Intervention, Economy, Quarantine. 


\section{Introdução}

Ao contrário do que geralmente acontece nos já conhecidos ciclos econômicas, as pandemias causam crises independentemente do sistema financeiro. Em virtude disso, é de extrema relevância analisar as consequências econômicas sentidas no advento deste tipo de evento. No artigo, pretendo desenvolver os efeitos na escala valorativa dos agentes e a mudança em sua preferência temporal, algo que inevitavelmente corresponderá a uma estrutura produtiva que não atende mais aos desejos e necessidades dos agentes econômicos. Usando como base a recente crise do Covid-19, será acrescentada a nossa análise os tipos de intervenção mais recorrentes em pandemias. Desta forma, poderemos ter uma visão global da crise, suas consequências, o que deve ser feito para mitigar seus efeitos e de que maneira a intervenção contribui para o agravamento da situação.

É importante compreender os custos implicados destas intervenções antes de levá-las a cabo, uma vez que seus efeitos não são facilmente distinguidos e podem gerar um dano maior do que aquele que se tenta remediar. Veremos de que maneira políticas de quarentena acabam por restringir a reestruturação econômica. Como o estabelecimento de preços máximos impede o fluxo de capital para as áreas de maior necessidade, em especial ao setor sanitário. Finalmente, de que maneira o resgate aos agentes insolventes e as políticas de subsídio contribuem para o agravamento do problema, tendo o potencial de transformar uma pequena e rápida crise em uma longa e forte recessão. $\mathrm{O}$ uso destas medidas acaba gerando decorrências colaterais como o risco moral que, por sua vez, modifica as expectativas dos agentes econômicos, levando-os a negligências pandemias futuras.

A demanda por intervenção estatal é muito grande em tempos de crise, inclusive por parte de economistas que se deparam com uma situação pouco conhecida, dando enormes poderes ao Estado para aplicá-las. Se este é o caso, é fundamental entender o tipo de crise que se dá em uma pandemia, assim como o resultado de medidas intervencionistas propostas. Acredito que este trabalho ajudará a compreender o real papel do Estado diante deste cenário.

\section{Crise Econômica}

Uma pandemia provocará mudanças na escala valorativa dos agentes econômicos. Os padrões de comportamento mudarão face ao problema, causando um câmbio nos custos incorridos para cada ação, ao passo que haverá uma redistribuição do capital entre os agentes. Ocorrerão efeitos similares a desastres naturais, onde o custo para permanecer em segurança provoca uma mudança orçamentária dos indivíduos. Ao mesmo tempo, os fins que o ser humano persegue e os meios necessários para alcançá-los serão alterados a um ritmo maior que a readequação da estrutura produtiva. Outros produtos passarão a ser mais demandados, como bens sanitários e alimentícios, e a própria preferência temporal dos agentes econômicos será modificada. A pandemia tem como resultado gerar uma crise econômica de forma exógena ao 
sistema ${ }^{1}$. Rapidamente, existirá uma estrutura produtiva que não atende mais aos desejos dos consumidores ${ }^{2}$.

O perigo de morte, somado à sucessiva mudança no cenário econômico, conduzirá a um grande aumento na incerteza, resultando na subida da taxa social de preferência temporal. Se Robinson Crusoé pensa que um temporal poderá destruir um bem de capital que pretendia construir, mas não poupará mais para esse projeto. Se pensa que poderá morrer, não terá por que continuar renunciando ao consumo presente em detrimento do futuro, consumindo o capital acumulado. A sociedade experimentará os efeitos característicos de uma "economia em regressão".

Em seu livro sobre os ciclos econômicos, Huerta de Soto comenta um trecho do livro "Capital and Time", de John Hicks, no qual é descrita a sequela da Grande Peste de Florença do século XIV, na preferência temporal da população. Na ocasião, a epidemia fez com que as pessoas pensassem que teriam uma menor esperança de vida, resultando em um consumo de capital (HUERTA DE SOTO, 2009, p. 276). Como se trata expressamente do assunto abordado neste trabalho, vale a pena apresentar o trecho no qual Hicks faz referência a esse acontecimento. Em suas palavras: "Bocaccio is describing the impact on people's minds of the Great Plague at Florence, the expectation that they had not long to live. 'Instead of furthering the future products of their cattle and their land and their own past labour, they devoted all their attention to the consumption of present goods'."'3 (HICKS, 1973, p. 12-13)

Efeitos intertemporais: dado ao aumento da preferência temporal, haverá um aumento relativo dos lucros das empresas que participam das etapas produtivas mais próximas ao consumo em relação as mais afastadas. Essa disparidade de lucros entre as distintas etapas do processo produtivo levará a uma diminuição dos investimentos nas etapas mais afastadas. Ao mesmo tempo, a subida da taxa de juros provocará uma diminuição do valor dos bens de capital, causando desinvestimento de tais indústrias. Por último, se manifestará o Efeito Ricardo. A maior procura por bens de consumo causará um aumento do preço dos bens de consumo a um ritmo superior ao aumento dos salários, implicando em uma diminuição dos salários reais e dos rendimentos dos fatores originários de produção, tornando interessante aos empresários substituir equipamento-capital por mão-de-obra.

A consequência inevitável será o achatamento da estrutura produtiva, agora menos capital intensiva, de maneira que a quantidade de bens de consumo, que chegam à etapa final, será

\footnotetext{
${ }^{1} \mathrm{O}$ sistema financeiro atual, por meio do mecanismo de reserva fracionária e do Banco Central, causa ciclos sucessivos de crises econômicas que são endógenas ao próprio sistema financeiro. É dizer, a própria maneira que atua os bancos é responsável por causar invariavelmente sua bancarrota. Isso não significa que não possa haver outras formas de crise económica, uma vez que a mesma se dá devido a um problema de descoordenação dentre produção e consumo. Ver o livro “Dinheiro, Crédito Bancário e Ciclos Económicos" (HUERTA DE SOTO, 2009).

${ }^{2} \mathrm{~A}$ análise realizada deste artigo não leva em consideração o efeito do advento de uma pandemia quando já existe uma bolha financeira. Esse enforque foi escolhido para que pudesse haver uma análise isolada do problema, de modo a contribuir para qualquer situação que se deem os supostos de uma pandemia aqui explorados.

${ }^{3}$ A tradução desta passagem para o português seria: “Bocaccio está descrevendo o impacto nas mentes das pessoas da Grande Praga em Florença, a expectativa de que elas não tinham muito tempo para viver. 'Em vez de promover os futuros produtos de seu gado, suas terras e seu próprio trabalho passado, eles dedicaram toda sua atenção ao consumo de bens presentes'."
} 
menor. Como resultado, haverá o empobrecimento generalizado da população, em especial dos trabalhadores, que verão seu salário diminuir em termos reais.

Efeitos intratemporais: haverá uma diminuição do ritmo de consumo nas empresas dedicadas a produzir bens de menor necessidade, fazendo com que baixem os preços de ditos bens. Isso refletirá em uma diminuição dos lucros contabilísticos nessas empresas, levando a liberar fatores produtivos. Ao mesmo tempo, aumentará a demanda nas empresas que se dedicam a produzir bens de maior necessidade, subindo o preço dos alimentos, equipamentos sanitários, bens hospitalares, serviços de telecomunicação etc., levando ao aumento dos lucros contabilísticos nestas empresas. Essa disparidade de lucros funcionará como um sinal indicador e como incentivo para que os empresários restrinjam seus investimentos em indústrias dedicadas a produzir bens de menor necessidade, para dedicá-los as indústrias que agora são mais valoradas pelos agentes. Algumas indústrias deverão aumentar de tamanho, enquanto outras deverão fechar. Isso levará a um aumento na demanda por fatores produtivos, indústrias mais valoradas, que serão supridos pelos fatores liberados nas indústrias que agora produzem bens menos demandados. Dessa forma, a estrutura produtiva será modificada para que possa atender aos desejos e necessidades dos agentes econômicos.

Enquanto dura o processo, os agentes econômicos experimentarão uma baixa em seu padrão de vida. Para que a readequação da estrutura produtiva possa ocorrer da maneira mais rápida e eficiente possível, deve pôr-se em prática as seguintes medidas: (1) Desregulamentação econômica, em especial no que diz respeito ao mercado laboral, que é um fator com maior adaptabilidade a diferentes tipos de trabalho; (2) Entorno institucional que fomente a poupança privada, de modo que o capital seja alocado onde os empresários identificam lucros potenciais. Nesse respeito, é importante que não ocorram pacotes de estímulos econômicos por parte do governo, que provocam o efeito crowding out ${ }^{4}$, e que atrai investimentos privados para títulos da dívida pública; (3) Livre exercício da função empresarial, de modo que o processo de criação e descobrimento de novas maneiras de solucionar o problema não seja bloqueado, uma vez que não será gerada a informação relevante para coordenar a sociedade. Assim, quanto mais flexível for a economia, mais rápida será a realocação de capital para reestruturar a produção e menos sofrido será para população.

Assim, é natural que países com maior nível de liberdade econômica sofram menos com pandemias historicamente. Na pandemia de 1918, causada pela Influenza, os países com a economia mais livres tiveram uma maior capacidade de suportar a chegada da crise e readequar sua estrutura produtiva, de modo que sua recuperação se deu mais rápida que de países mais regulados (GELOSO; PAVLIK, 2020).

${ }^{4} \mathrm{O}$ efeito crowding out é a situação na qual o aumento dos gastos públicos leva a diminuição dos investimentos no setor privado. 


\section{Quarentena}

Quando existe uma política de quarentena, esse processo é paralisado. A estrutura produtiva da sociedade sofre um engessamento, em maior ou menor medida, dependendo do grau de quarentena aplicada. A coerção estatal impede o livre exercício da função empresarial, detendo o processo de coordenação social. Os fatores produtivos que poderiam estar sendo realocados para resolver o problema já não estão disponíveis. Os setores beneficiados se veem limitados em aumentar o número de trabalhadores com o objetivo de aumentar a produção. O capital não consegue ir para as áreas onde é mais produtivo e, portanto, mais necessário.

Ao haver uma imposição para que não se produza, ou seja, proibição de atuar empresarialmente, os efeitos intertemporais serão aumentados. Através da coerção, se induz artificialmente uma taxa de preferência temporal extremamente alta. A sociedade não pode parar de consumir (nem que seja para subsistência), ao passo que o volume produzido será muito mais baixo que antes. Para suprir suas necessidades, o capital começará a ser lapidado e consumido. Um processo descivilizador entrará em cena e, só cessará, quando terminar a política de quarentena e os seres humanos se vejam livres para atuar empresarialmente.

Caso sejam postas em prática políticas que visam impedir a demissão dos trabalhadores, o problema se agravará. Os fatores originários de produção, que poderiam estar migrando para as áreas mais demandadas, se encontram indisponíveis, dando lugar a uma escassez relativa de mão de obra. Os setores de maior demanda passarão a aumentar os salários com o objetivo de atrair mais trabalhadores. Porém, dificilmente, um trabalhador que ganha o privilégio de ficar em casa, recebendo sem trabalhar, aceitará um novo trabalho, fazendo com que os salários das empresas lucrativas subam ainda mais para atrair tais trabalhadores. Se consumirá cada vez mais capital para uma menor produtividade. Mesmo com essa grande alta nos salários nominais, o Efeito Ricardo não entrará em cena, ou entrará de forma modesta. O movimento natural seria a troca de equipo-capital por fator trabalho, dado a diminuição dos salários reais e a escassez relativa de equipo. No entanto, os fatores originários produção não estarão liberados para substituir o equipo capital. É possível que a quebra das demais empresas alivie um pouco a situação, podendo ser aproveitado alguns bens de capital conversíveis e fatores originários de produção (estes últimos dependerão da política de seguro-desemprego adotada). Ao impedir a demissão de trabalhadores, o Estado agrava o problema, levando a uma grande diminuição na produção e a uma enorme alta nos preços.

Em seguida explicaremos com detalhe o problema das políticas de preço máximo. Todavia, vale ressaltar que, quando se aplica tal política, o empresário se verá limitado a aumentar os salários muito antes. Rapidamente, os custos superarão os preços, levando à inevitável escassez.

Por fim, a política de quarentena gera uma descoordenação tão grande, que inevitavelmente vem seguida de várias outras intervenções, que vão agravando a tragédia. Assim, o problema que se tenta combater é dificultado pela própria ação coactiva dos Estados, tardando mais com que se solucione e gerando uma série de outros problemas no caminho. O Estado, em última instância, acaba transformando toda a estrutura produtiva em uma "economia de guerra". 


\section{Preço Máximo}

Apesar de ser um dentre diversos tipos de intervenção quando nos referimos a políticas públicas, o estabelecimento de preços máximos é uma das mais recorrentes medidas adotadas quando uma sociedade se depara com uma crise econômica. Quando epidemias levam a crises, ou as desencadeia, o preço máximo seguramente aparecerá entre a política pública de vários Estados, como foi observado com de maneira sistemática na crise do Covid-19. Por essa razão, vale a pena discutirmos as consequências e os custos implicados de tal medida.

O preço é o sinal no mercado que guia o empresário em sua tomada de decisão, refletindo da melhor forma possível a valoração dos agentes e permitindo-os realizar o cálculo econômico. Dessa forma, é fundamental que os preços não sejam distorcidos, pois levará aos empresários a erros de cálculo econômico, alocando recursos onde não deveriam, e deixando de alocar nas áreas onde a sociedade mais necessita. Como descreve Rothbard, "o controle de preços distorce a produção e alocação de recursos e fatores na economia, prejudicando mais uma vez a maior parte dos consumidores." (ROTHBARD, 2012, p. 56)

Quando existe uma política de preços máximos, os empresários não tomam conhecimento de que determinado bem está aumentando seu valor de mercado. É dizer, o não aumento no preço fará com que o não seja transmitido aos agentes seu real valor para a sociedade, havendo um erro de cálculo econômico que indicará aos empresários que não existe lucro a perseguir. Portanto, não irão atuar para levar os recursos ali onde são necessários. Quando existe uma situação urgente de pandemia, onde a sociedade necessita que a maior parte dos recursos sejam mobilizados para alguns fins específicos, o dano causado é muito maior. É mais, não apenas deixará de aumentar a produção desses bens de primeira necessidade, como haverá uma diminuição da produção desses bens. Como o valor dos fatores de produção derivam do valor estimado dos bens de consumo finais que estes irão produzir, a fixação de preços máximos tem o efeito de criar uma situação na qual os custos de produção superam ao preço de venda, causando uma fuga de recursos justamente onde são mais necessários. A consequência inexorável será a escassez.

Mises faz referência à importância de se aceitarem os preços mais altos, quando existe uma mudança súbita nas circunstâncias, não se deixando levar pela aparente situação em que alguém está lucrando muito com a situação. Em suas palavras:

Eventos exteriores, capazes de afetar a oferta e a demanda, às vezes ocorrem tão repentina e inesperadamente que as pessoas costumam dizer que ninguém, razoavelmente, poderia têlos previsto. Nesse caso, os invejosos podem considerar injustificáveis os lucros decorrentes dessas mudanças. entretanto, tais juízos de valor não mudam a realidade. um homem doente prefere ser curado por um doutor que cobra caro pelos seus serviços do que ficar sem assistência médica. Se não fosse assim, ele não consultaria o médico. (MISES, 2010, p. 758)

No entanto, se é permitida a subida do preço, refletindo a maior valoração que a sociedade dá aos bens e, portanto, sua maior demanda, põe-se em marcha o seguinte processo. Muito empresários verão esse preço como uma grande oportunidade de negócio, mobilizando os recursos para que os bens mais necessários cheguem ao consumidor e satisfaça suas 
necessidades. Conforme aumente o volume de produção, baixarão os preços, em um processo que não se detém até que os preços igualem aos custos marginais somada a taxa de preferência temporal. Logo, é um processo que costuma ser rápido, dado que existe um incentivo, refletido em uma vantagem temporal, aos empresários que mais rápido convertam o capital em bens econômicos.

Apesar da intenção revelada de proteger aos consumidores, a fixação de preços máximos os deixará sem o produto. Para solucionar o problema, o estado costuma aplicar um nível maior de intervenção, organizando sistemas de distribuição. São estabelecidas filas (onde só compram os primeiros), cartilhas de racionamento, amizade (onde apenas as pessoas próximas do fornecedor adquirem o bem) e, finalmente, saques e violência.

\section{Resgates e Subsídios}

Quando o governante decide aplicar políticas de quarentena, que impedem de maneira direta os empresários e os trabalhadores de produzirem, e indiretamente, os consumidores de comprar seus produtos, é levantada a questão: o governante deve subsidiar aqueles que foram afetados pelo resultado de seus mandatos?

Não é uma questão trivial. Se uma pessoa sequestra outra por uma "boa causa", ela deveria prover os meios para que a vítima possa subsistir? Os burocratas, portanto, deveriam desfazer-se de seus próprios recursos para compensar aos afetados. No entanto, não é essa a situação que se apresenta na vida real. No caso de subsídio, o governante usará do aparato coercitivo para tirar de uns para dar a outros, havendo uma relação de subserviência dos que continuam a produzir e aqueles que não mais produzem. Assim, por mais que os afetados não tenham culpa direta de sua tragédia, tampouco tem aqueles que devem pagar pela tragédia alheia.

É importante lembrar que a chegada de uma epidemia invariavelmente modificará a escala valorativa dos agentes, levando a necessidade de adequação da estrutura produtiva. O agravamento da situação por políticas Estatais de combate à epidemia não significa, ipso facto, que uma empresa deixaria de falir em sua ausência. Esse tipo de medida acabará, como qualquer política intervencionista, gerando mais dano do que benefícios para a sociedade.

Quando o governante decide subsidiar a um grupo, esta passa a atuar fora da lógica de mercado. Tomemos como exemplo o dono de um hotel que perdeu os seus hóspedes devido a uma política de quarentena. O dono passará a perceber perdas contáveis em seus balanços, e caso não tenha capital para suportar essas perdas, entrará em falência. Tal é o caso da recente crise do Covid-19, onde havia inúmeros empresários alavancados e sem capacidade para manter seus negócios.

Em primeiro lugar, caso tenha que vender seu hotel, não necessariamente implicará em um empobrecimento da população. Quem faliu foi o dono, mas o bem de capital continua intacto e poderá ser aproveitado por outro empresário com capacidade financeira para passar o período de crise. Assim, se o mercado acredita que a crise não modificará a preferência dos consumidores a ponto de deixarem de frequentar hotéis, esse bem de capital será aproveitado 
e mantido, sendo até mesmo convertido. Podendo, por exemplo, ser usado como hospital durante o período de crise.

Em segundo lugar, os prejuízos sentidos pelo dono do hotel atuarão como incentivo para que modifique seus investimentos. Em um processo dinâmico de rivalidade, os empresários alocarão o capital ali onde voltarão a ter lucros, enriquecendo a sociedade como um todo. Ao subsidiar o empresário, é eliminado o incentivo para modificar sua produção. Passa-se a incentivar o engessamento econômico, consumindo os recursos da sociedade para manter um negócio improdutivo. É uma política que beneficia coercitivamente aos ineficientes em detrimento dos eficientes, ao passo que distorce a estrutura produtiva da sociedade. Como exposto por Rothbard, "os subsídios prolongam a vida das empresas ineficientes às custas das eficientes, distorcem o sistema produtivo e dificultam a mobilidade dos fatores dos locais menos para os mais produtivos. Prejudicam enormemente o mercado e impedem a plena realização dos desejos dos consumidores" (ROTHBARD, 2012, p. 188). Quanto maior for esse subsídio, maior será o incentivo para que a produção não se modifique para atender as reais demandas dos consumidores, diminuindo, ceterus paribus, o padrão de vida de toda a população.

Em terceiro lugar, os trabalhadores do hotel não serão liberados, levando a uma escassez relativa de fatores originários de produção, que por sua vez gerará um problema de escassez relativa de bens e serviços de consumo na qual explicamos anteriormente.

O quarto problema diz respeito ao risco moral. Segundo define o economista Jörg Hülsmann:

Moral hazard is the incentive of a person A to use more resources than he otherwise would have used, because he knows, or believes he knows, that someone else B will provide some or all of these resources. The important point is that this occurs against B's will and that B is unable to sanction this expropriation immediately. The mere incentive to rely on resources provided by others is not per se problematic. ${ }^{5}$ (HÜLSMANN, 2008)

Os subsídios, portanto, mexem com as expectativas racionais dos agentes. Quem recebe o subsídio se encontra em uma situação na qual pode externalizar os prejuízos em seu ativo, enquanto recebe na integra os ingressos do passivo. Surge um problema da tragédia dos comuns. Ao fornecer solvência para alguns agentes, de modo compensá-los por uma política governamental, ou pela falta da mesma que uma natural situação de pandemia pode gerar, os mesmos não terão incentivos para se resguardarem para esse tipo de evento no futuro. A ação humana envolve incerteza e o homem está constantemente buscando maneiras de diminuí-la. Assim, instrumentos financeiros como hedge ou a contratação de seguradoras, serão desincentivados, levando a irresponsabilidade econômica. Um agente resgatado não apenas verá como aceitável se manter alavancado, como receberá incentivos para aumentar sua exposição. Deve-se reconhecer que o fato das pessoas não se prepararem para um evento catastrófico é de

\footnotetext{
${ }^{5}$ Esta passagem poderia ser traduzida para o português da seguinte maneira: “Risco moral é o incentivo de uma pessoa A para usar mais recursos do que de outra forma teria usado, porque sabe ou acredita que sabe que outra pessoa B fornecerá alguns ou todos esses recursos. O ponto importante é que isso ocorre contra a vontade de B e que B é incapaz de sancionar essa expropriação imediatamente. O mero incentivo para contar com os recursos fornecidos por outros não é, por si só, problemático".
} 
sua inteira responsabilidade, sendo resultado de suas próprias ações. Remediar a posteriori, por meio da coerção institucional, não é apenas errado, ao cobrar dos mais preparados o custo de terceiros irresponsáveis, como leva a institucionalizar esse tipo de comportamento. Epidemias não são eventos únicos ao longo da história, e ainda que fossem, tais medidas aleijam a ordem espontânea que a sociedade a de formar para prevenir e remediar eventos futuros.

É interessante que o risco moral não se dá apenas na esfera privada, mas também no que diz respeito às estruturas governamentais. Se os estados de uma federação como os EUA ou os países da EU são respaldados pelo FED ou BCE, os mesmos terão incentivos para manter as respectivas intervenções econômicas e suas políticas de subsídio, posto que os custos serão divididos entre os demais membros da federação. Ceterus paribus, os Estados não realizarão os custos econômicos e manterão as intervenções por mais tempo. Como aponta o professor Bagus, os Estados do sul da Europa que haviam sido resgatados no contexto da crise de 2008, terminaram por não reduzir o déficit público e, com o advento da crise sanitária do Covid-19, adotaram a política de advogar pela socialização dos altos custos de sua quarentena entre toda a comunidade europeia (BAGUS, 2020). Na figura a seguir (Figura 1), podemos observar a evolução dos Déficits e Superávits Governamentais em porcentagem do PIB, entre os anos de 2014 e 2018, de Itália, França e Espanha, em comparação com Alemanha e os Países Baixos, e a comparação destes mesmos países, com relação a sua dívida pública em relação à porcentagem do PIB.

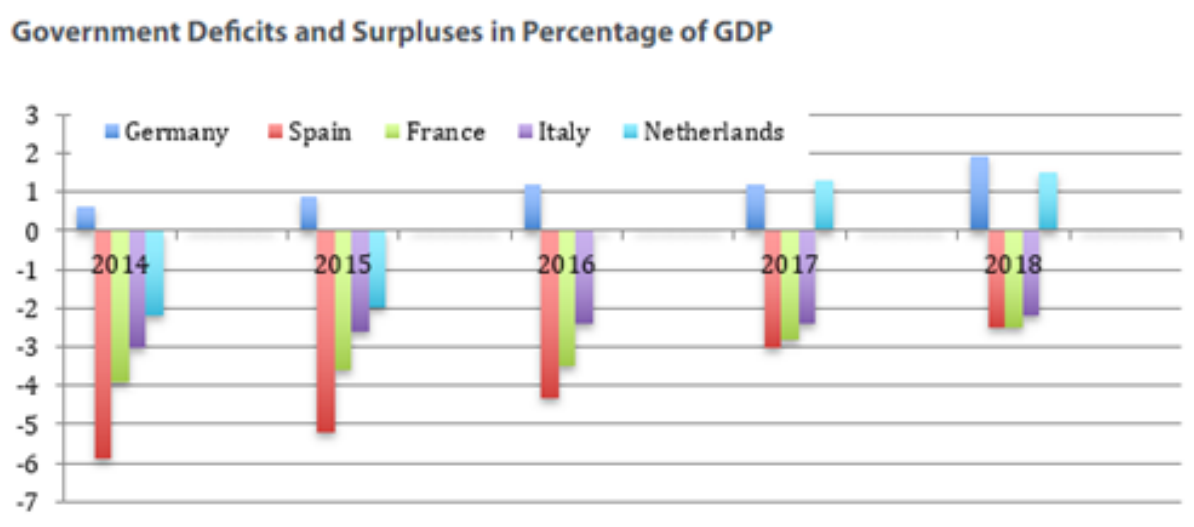

Government Debts in Percentage of GDP

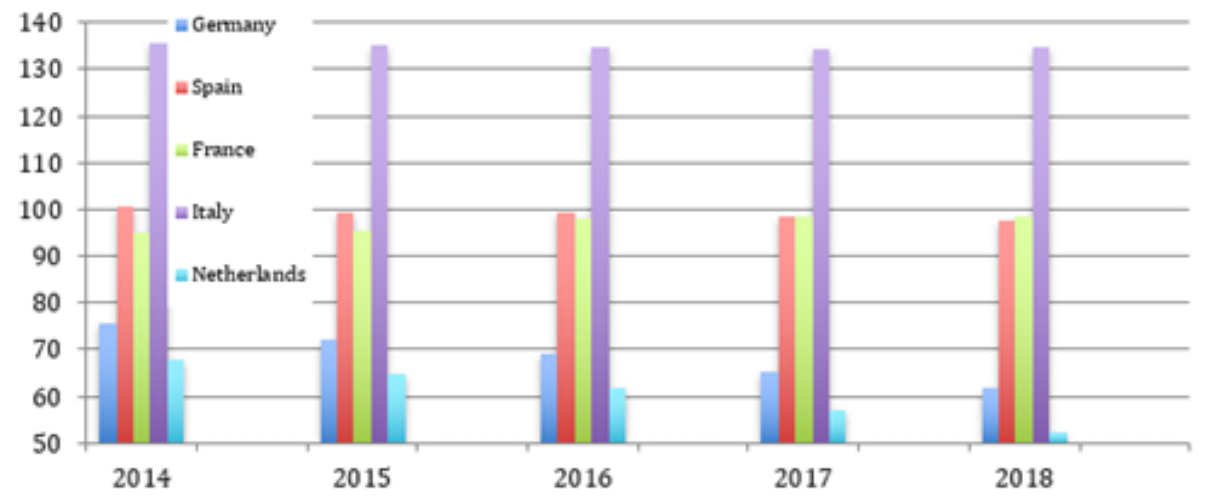

Figura 1. Déficits e Superávits e Dívida Pública com relação ao PIB entre os anos 2014 e 2018 de Alemanha, Países Baixos, Espanha, Itália e França

Fonte: Bagus (2020). 
Em quinto lugar, o subsídio distorcerá a lógica de mercado, na qual um produtor deve fornecer um bem desejado pelo consumidor para obtenção de lucro. Agora, muitas empresas verão seus ganhos vindos por meios políticos, de modo que invés de atuar na produção de cada vez melhores bens e serviços de consumo, atuarão de modo a triunfar na luta política por recursos. Assim, Rothbard sinaliza que "o sistema de subsídio promoveria as habilidades predatórias desses indivíduos e penalizaria os produtivos. em suma, o sistema de subsídio governamental promove a ineficiência na produção e a eficiência na coerção e na subserviência, ao penalizar a eficiência na produção e a ineficiência na predação." (ROTHBARD, 2012, p. 189-90).

Em última instância, a demanda por subsídios e concessão de crédito atrasará a inevitável quebra de muitas empresas ao custo de piorar a presente crise sanitária. Ao subsidiar as empresas ineficientes, o capital não é realocado onde é mais demandado pelos agentes econômicos. Esse cenário conduzirá a pressões inflacionárias e ao início de uma expansão creditícia, cuja análise não é o objeto de estudo do presente trabalho. Vale ressaltar, entretanto, que dita política causará uma subida generalizado dos preços dos bens de consumo a um ritmo superior ao preço dos fatores de produção, levando ao Efeito Ricardo e a uma economia menos capital intensiva. Finalmente, esse tipo de medida implicará em um consumo de capital que, a primeiro momento, será responsável pela diminuição do valor dos bens de capital presentes na economia. Tais bens de capital, como explica Hayek, seguirão existindo por um determinado período de tempo. O problema maior ocorrerá quando essa redução de capital leve ao que não seja possível amortizar os bens em questão, sucedendo uma redução do equipo em termos físicos. Em consequência, a sociedade se verá mais pobre, ao passo que haverá graves problemas de desemprego (HAYEK, 1967, p. 93).

\section{Seguro-Desemprego}

Vale a pena comentar sobre o seguro-desemprego governamental, uma vez, que na recente crise do Covid-19, foi uma das medidas mais recorrentemente observadas em todo mundo, havendo, inclusive, políticas de transferência de recursos para pessoas que não estavam trabalhando no início da crise. Essa modalidade de transferência é apenas uma variante do que acabamos de explicar, caindo nos mesmos problemas fundamentais. Há um aumento da utilidade marginal do ócio, criando um incentivo para o trabalhador manter-se desocupado. Os beneficiados não se veem incumbidos de atuar empresarialmente para sair dessa situação, de modo enrijecer o processo de saída da crise e diminuir o padrão de vida geral da população.

Essa política não faz sentido, uma vez que a quebra de um negócio não deveria implicar no desemprego por falta de postos de trabalho. Apesar da situação econômica descrita, o trabalho é um fator de produção não específico, precificado pelo valor descontado de sua produtividade marginal (VDPM), de modo que se adapta a uma enorme variedade de tipos de trabalho. Sendo assim, a liberação dos fatores originários de produção fará com que diminua seus rendimentos, dada a diminuição de sua produtividade e o aumento da taxa de juros, levando a sua alocação nas demais indústrias com a consequente substituição de equipamento-capital por 
fator trabalho. Não apenas isso, as necessidades humanas são ilimitadas, de modo que a baixa dos rendimentos dos fatores originários implica no aparecimento de várias empresas, agora rentáveis. O motivo pelo qual isso não ocorre é porque o governo mantém simultaneamente políticas de salário-mínimo. Assim, todo trabalhador que tiver seu valor de mercado abaixo do salário-mínimo estabelecido, estará proibido de trabalhar.

\section{Conclusão}

O advento de uma pandemia invariavelmente provocará distorções na estrutura produtiva que serão maiores ou menores de acordo com a doença em questão. As necessidades mudarão e a preferência temporal dos agentes também, dando lugar a uma estrutura produtiva insustentável e que deve sofrer o processo de reajuste. Dentro deste marco, o Estado atuará.

Desta forma, o Estado deve optar por diminuir sua presença na economia, evitando o efeito crowding out e flexibilizando o mercado laboral, para que mais rapidamente possa haver a reestruturação econômica e menos sofrido seja este processo para a população. Em contrapartida, quando o Estado atua ativamente no processo, por meio de intervenções, os efeitos intertemporais e intratemporais são aumentados, de modo que a reestruturação se torne lenta e sofrida, podendo ser atrasada até o fim de ditas medidas. Não apenas isso, aumenta-se o consumo de capital, o que achata e estreita ainda mais a estrutura produtiva, empobrecendo consideravelmente a população.

A intervenção acaba por gerar consequências não intencionadas que vão em contra daqueles pretendidos desde o ponto de vista daquele que às aplica, dando lugar a um ciclo de sucessivas intervenções. A imposição de preços máximos impede a chegada de recursos para combater a doença, tornando escassos justamente os bens de maior necessidade. As medidas de quarentena, dentre seus diversos efeitos, impedem a liberação dos fatores originários de produção, impossibilitando sua realocação e dificultando a necessária troca de equipamentocapital por mão de obra. Os resgates e subsídios aos agentes são talvez um dos maiores problemas, dado que impedem a liquidação de projetos não lucrativos e a liberação dos fatores originários. Costumam ser financiados por meios inflacionários, levando aos conhecidos ciclos econômicos e provocam um risco moral extremamente lesivo no combate a futuras pandemias.

Assim, a função que o Estado deve desempenhar no combate a uma pandemia e à crise, econômica por ela provocada, deve ser a de permitir o funcionamento dos processos de mercado, resistindo à tentação de aplicar intervenções, diminuir o seu peso na economia e fomentar um entorno institucional de poupança e livre exercício da função empresarial. 


\section{Referências}

BAGUS, Philipp. The COVID-19 Crisis Is Driving the EU to the Brink. Disponível em: https://mises.org/wire/ covid-19-crisis-driving-eu-brink. Acessado em: 10 jun 2020.

BOLOGNA PAVLIK, Jamie; GELOSO, Vincent. Economic Freedom and the Economic Consequences of the 1918 Pandemic. Disponível em: https://ssrn.com/abstract=3608178. Acessado em: 18 jul 2020.

HAYEK, Friedrich August von. Prices and Production. Nueva York: Augustus M. Kelly, 1967.

HICKS, John Richard. Capital and Time: A Neo-Austrian Theory. Oxford: Clarendon Press, 1973.

HUERTA DE SOTO, Jesús. Dinero, Crédito Bancario y Ciclos Economicos. Madrid: Unión Editorial, 2009.

HÜLSMANN, Jörg Guido. What Causes Moral Hazard? The Free Market, v. 26, n. 4, p. 1-6, 2008.

MISES, Ludwig von. Ação Humana: Um Tratado de Economia. São Paulo: Instituto Ludwig von Mises Brasil, 2010.

ROTHBARD, Murray Newton. Governo e Mercado: A Economia da Intervenção Estatal. São Paulo: Instituto Ludwig von Mises Brasil, 2012.

RECEBIDO: 25 DE JULHO 2020

APROVADO: 14 DE SETEMBRO 2020 